\title{
Quaternized wood as sorbent for hexavalent chromium
}

\begin{abstract}
The potential of quaternized wood (QW) chips in removing hexavalent chromium from synthetic solution and chrome waste under both batch and continuous-flow conditions was investigated. Sorption was found to be dependent on $\mathrm{pH}$, metal concentration, and temperature. QW chips provide higher sorption capacity and wider $\mathrm{pH}$ range compared with untreated wood chips. The equilibrium data could be fitted into the Langmuir isotherm model, and maximum sorption capacities were calculated to be 27.03 and $25.77 \mathrm{mg} / \mathrm{g}$ in synthetic chromate solution and chrome waste, respectively. The presence of sulfate in high concentration appeared to suppress the uptake of chromium by QW chips. Column studies showed that bed depth influenced the breakthrough time greatly whereas flow rate of influent had little effect on its sorption on the column.
\end{abstract}

Keyword: Biosorption; Chemical modification; Hexavalent chromium; Wood 